\title{
Survey of Intestinal Pathogens from Immigrant Children
}

\author{
R. G. THOMPSON, J. G. P. HUTCHISON, NATALIE M. JOHNSTON
}

British Medical fournal, 1972, 1, 591-594

\section{Summary}

Four thousand immigrant schoolchildren were screened by using a concentration method on a single faecal specimen for intestinal helminths; $1,468(37 \%)$ were positive. Carriage rates were highest $(51 \%)$ in children from the West Indies, in whom trichuris (75\% of carriers) and ascaris (40\% of carriers) predominated; carriage of two or more species was common (36\% of carriers). Carriage of worms was low in children from Kenya $(16 \%)$ and Uganda ( $7 \%$ ). Children from South-east Asia, predominantly from India and Pakistan, had carriage rates between 30 and $40 \%$; girls and boys from Pakistan differed significantly in their carriage patterns of hookworm (commoner in boys) and hymenolepis and ascaris (commoner in girls).

Five salmonellas were found, two of which were Salmonella typhi, and five Shigella sonnei were isolated. No isolates were made of Vibrio cholerae (classical or El Tor biotypes) from 590 South-east Asian children.

\section{Introduction}

With the entry into the Birmingham region in the past few years of many immigrants of school age, it has been the policy to examine all newly arrived children before they enter school. As part of this screening programme the Public Health Laboratory, Birmingham, undertook to examine a single faecal sample for intestinal parasitic ova, cysts, and pathogenic bacteria. The screening procedure has now become routine, and the following account is an analysis of 4,000 cases, between January 1968 and October 1970, which is part of the total number so far examined. Initially, we were screening faeces only for enteric pathogens and helminth ova; however, as the survey progressed, screening for protozoal cysts was included (2,709 specimens). More

Regional Public Health Laboratory, East Birmingham Hospital, Birmingham B9 5ST

R. G. THOMPSON, M.R.C.s., L.R.C.P., Assistant Bacteriologist (Present address: Public Health Laboratory, New Cross Hospital, Wolverhampton WV10 0QP)

J. G. P. HUTCHISON, M.D., F.R.C.P., M.R.C.PATH., Director

City of Birmingham Public Health Department, Birmingham

NATALIE M. JOHNSTON, L.R.C.P. \& S.ED., D.P.H., Senior Administrative Medical Officer for Personal and Child Health Services recently methods were added to discover possible cholera "carriers"; this survey was confined to 590 immigrants from the Indian subcontinent, where cholera is endemic and therefore carriage rather more likely than from other areas.

\section{Methods}

Bacteriological.-For the detection of enteric pathogens a small portion of faeces was inoculated into selenite enrichment medium and, after overnight incubation, plated out on to desoxycholate citrate medium. Further investigation of nonlactose-fermenting colonies was carried out by the usual routine methods. The screening methods used for the detection of cholera vibrios was that recommended by Carpenter (1966) and more recently modified to include the use of T.C.B.S. medium (Oxoid).

Helminths and Cysts. - A concentration method (Thompson, 1972) was used. Some hookworm ova were cultured to the infective larval stage for identification by the Harada-Mori technique-that is, the test-tube filter-paper method recorded by Sasa et al. (1958) and Hsieh (1963).

\section{Results}

Bacterial Pathogens. - In the total of 4,000 samples examined, five children yielded a Salmonella species and five Shigella sonnei. These were distributed as follows: Pakistan, 1,424 samples, 1 had Sh. sonnei; India, 795 samples, 1 had S. typhi, Vi phage type $A$, and 1 had $S$. liverpool; West Indies, 1,058 samples, 1 had $S$. derby and 3 Sh. sonnei; Kenya, 475 samples, 1 had $S$. virginia and 1 Sh. sonnei; South Africa, 16 samples, 1 yielded S. typhi which was phage untypable. There is little in these findings to confirm that the pathogens isolated came from abroad. Of the two $S$. typhi isolated, one was the common wild type $A$ and the other untypable. The other salmonellae and the shigellae may as well have been acquired here as elsewhere. No Vibrio cholerae, classical or El Tor biotypes, were isolated from 590 children, of whom 162 were Indians and 428 were Pakistanis.

Helminth Ova.-Ova of the whipworm (Trichuris trichiura), the roundworm (Ascaris lumbricoides), the dwarf tapeworm (Hymenolepis nana), the threadworm (Enterobius vermicularis), the blood fluke (Schistosoma mansoni), and hookworm species (Ancylostoma and Necator) were detected. In a total of 4,000 faecal samples, 1,468 were positive for helminth ova of one or more species, giving a crude infestation rate of $37 \%$.

TABLE I-Infestation Patterns of the Major Populations Surveyed

\begin{tabular}{|c|c|c|c|c|c|c|c|c|c|c|c|c|}
\hline \multirow{2}{*}{\multicolumn{3}{|c|}{ Country }} & \multirow{2}{*}{ Sex } & \multirow{2}{*}{$\begin{array}{c}\text { Total } \\
\text { Examined }\end{array}$} & \multirow{2}{*}{$\begin{array}{l}\text { Children } \\
\text { Positive* }\end{array}$} & \multicolumn{7}{|c|}{ Number $(\%)$ of Positives Carrying: } \\
\hline & & & & & & Hookworm & Hymenolepis & Ascaris & Trichuris & Enterobius & Schistosoma & \\
\hline $\begin{array}{ll}\text { Pakistan } & . . \\
\text { India } & . . \\
\text { Hong Kong } \\
\text { Woest Indies } \\
\text { Kenya } \\
\text { Uanda }\end{array}$ & $\begin{array}{l}. . \\
. . \\
\ddot{.} \\
\ddot{.}\end{array}$ & $\begin{array}{l}. . \\
\ldots \\
\ldots \\
\cdots \\
\cdots\end{array}$ & $\begin{array}{l}\text { M. } \\
\text { F. } \\
\text { M. } \\
\text { F. \& F. } \\
\text { M. \& F. } \\
\text { M. \& F. } \\
\text { M. \& F. } \\
\text { M. \& F. }\end{array}$ & $\begin{array}{r}1,194 \\
230 \\
448 \\
347 \\
36 \\
1,058 \\
475 \\
67\end{array}$ & $\begin{array}{c}476(40) \\
72(31) \\
158(35) \\
103(30) \\
16(44) \\
539(51) \\
74(16) \\
5(7)\end{array}$ & $\begin{array}{r}295(62) \\
18(25) \\
99(63) \\
51(50) \\
2(13) \\
139(26) \\
14(19) \\
0\end{array}$ & $\begin{array}{c}118(25) \\
26(36) \\
46(29) \\
40(39) \\
0 \\
0 \\
17(23) \\
0\end{array}$ & $\begin{array}{r}103(22) \\
23(32) \\
19(12) \\
17(17) \\
7(44) \\
216(40) \\
21(28) \\
4(80)\end{array}$ & $\begin{array}{c}54(11) \\
11(15) \\
5(3) \\
4(4) \\
12(75) \\
418(78) \\
24(32) \\
1(20)\end{array}$ & $\begin{array}{l}10(2) \\
3(4) \\
3(2) \\
5(5) \\
1(6) \\
0 \\
4(5) \\
0\end{array}$ & $\begin{array}{l}1(0 \cdot 2) \\
0 \\
0 \\
0 \\
0 \\
1 \\
0 \\
0\end{array}(0 \cdot 2)$ & $\begin{array}{c}92(19) \\
8(11) \\
12(8) \\
12(12) \\
5(31) \\
194(36) \\
5(7) \\
0\end{array}$ \\
\hline Total & .. & .. & & 3,855 & $1,443(37)$ & 618 & 247 & 410 & 529 & 26 & 2 & 328 \\
\hline
\end{tabular}

* Number and percentage (in parentheses) of children infested in each population.

* Number and percentage (in parentheses) of children infested in each population.
Mixed infestation column is the number $(\%)$ of children who harboured two or more species of helminth; these are also included under the single species columns. 


\section{Geographical Source of Parasites}

The regional classification outlined in the W.H.O. Report (1964), with minor modifications, was used. The countries from which the children in the survey came are given below. However, for simplicity only those populations contributing 20 or more children to the total are included in Table $I$ and in Figs. 1-5 relating to multiple infestation.
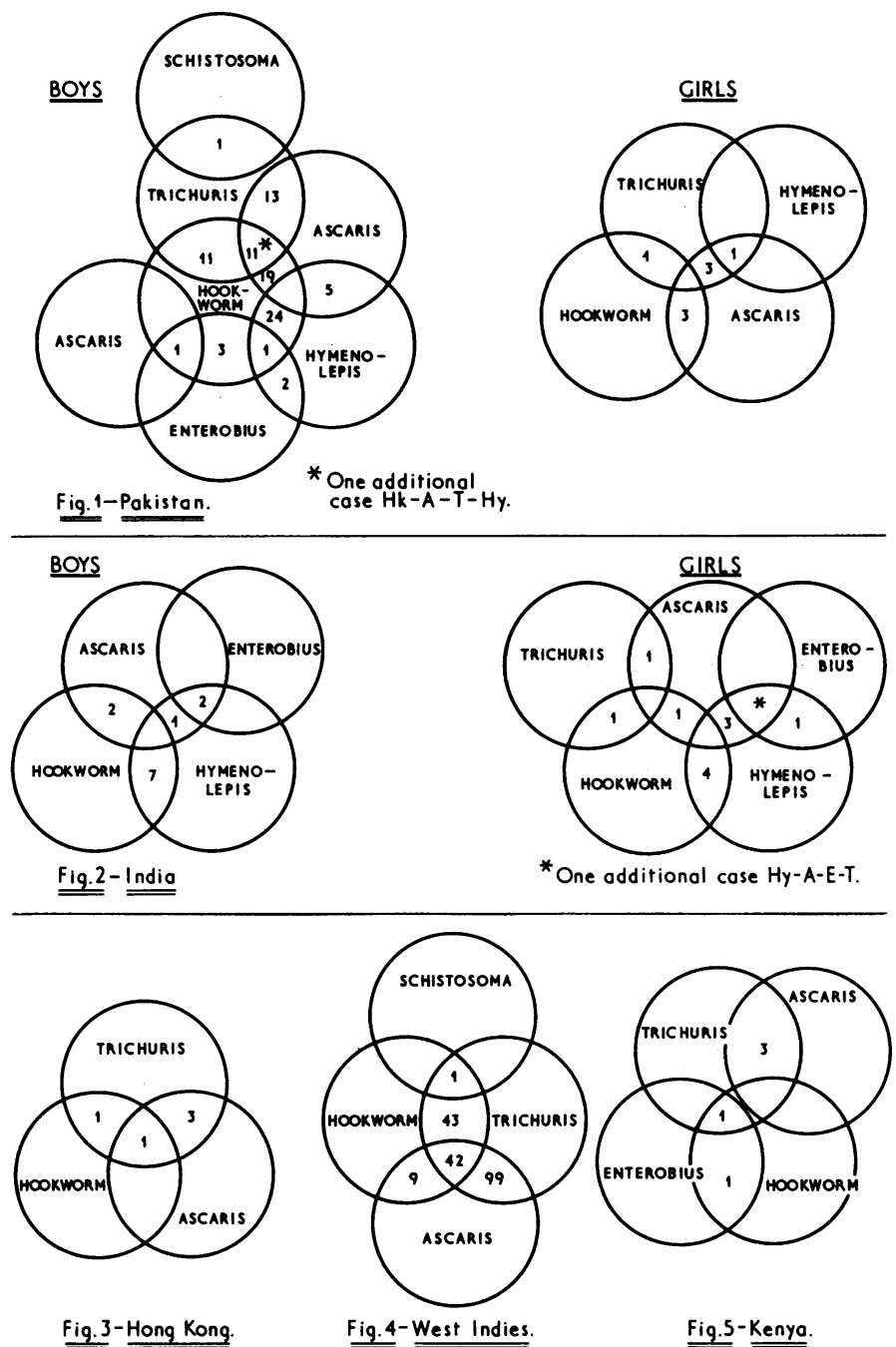

FIGs. 1-5-Patterns of multiple infestation in children from Pakistan, India, Hong Kong, West Indies, and Kenya.

\section{SOUTH-EAST ASIA}

Over half the children $(2,264)$ in the survey came from Southeast Asia, mainly from Pakistan, India, and Hong Kong. The detailed findings in these are given in Table $I$.

Pakistan.-The age range was 3 to 16 years. The male : female ratio was $5: 1$. On average the boys were older than the girls (median age of girls, 8 years; median age of boys, 11 years). The infestation pattern is shown in Table $I$; because of obvious differences in numbers and infestation rates boys and girls are shown separately. Of note is the carriage of helminths by $\mathbf{4 0} \%$ of boys and $31 \%$ of girls, a significant difference $\left(\chi^{2}=5.84\right.$, $P<0.02)$. Hookworm carriage in boys $(62 \%$ of all carriers) is much higher than in girls $(25 \%)\left(\chi^{2}=35.0, P<0.001\right)$, a highly significant difference. On the other hand, girls have higher infestation rates for both hymenolepis (36\%) and ascaris $(32 \%)$ than boys ( $25 \%$ and $22 \%$ respectively); these figures are significantly different in boys and girls. Mixed infestations of two or more types of worm are slightly more common in boys
(19\% of carriers) than girls ( $11 \%$ of carriers)-this difference is not of itself significant. In the boys carriage of hookworm with hymenolepis or ascaris or trichuris each amounts to $2-5 \%$ of carriers; carriage of hookworm with both trichuris and ascaris is present in 3\% of carriers; carriage of ascaris with trichuris amounts to $3 \%$ of carriers. In girls the number of mixed infestations is small (eight instances) but hookworm with ascaris $(4 \%)$ and ascaris with trichuris $(4 \%)$ constitute the two largest groups. A more detailed picture of the mixed infestations is shown in Fig. 1.

India.-The age range was 4-18 years. The number of boys and girls was about equal (male : female $=1 \cdot 3: 1$ ) with a similar age frequency distribution. The infestation pattern of this population is given in Table I. Although there is little difference in age distribution and infestation rate, males and females are shown separately by way of comparison with those from Pakistan, their closest geographical neighbour. The mixed infestations are shown in Fig. 2. The most frequent mixtures are hookworm with hymenolepis (4\% of carriers) in both boys and girls, and hymenolepis with ascaris (3\% of carriers) in girls. In this population the carriage of helminths by both boys and girls is similar, $35 \%$ of boys and $30 \%$ of girls. Hookworm carriage is higher in boys (63\% of all carriers) than girls $(50 \%)$ and this difference is probably significant $\left(\chi^{2}=4.4,0.05>\mathrm{P}>\right.$ $0.02)$. Girls carried hymenolepis $(39 \%)$ and ascaris $(17 \%)$ more frequently than boys $(29 \%$ and $12 \%$ respectively), but these differences are not significant although similar in direction to those found in the Pakistani population. Mixed infestations are slightly less frequent among boys $(8 \%)$ than girls $(12 \%)$. The trend towards higher carriage rates for hymenolepis and ascaris in the girls of both Pakistan and India is maintained.

HongKong.-This was a small population; the age frequency was predominantly from 11 to 15 years ( 32 cases) with 11 of the 12 positive cases in this range. The male : female ratio was $1.6: 1$. The infestation pattern is shown in Table $I$, and the pattern of mixed infestations is shown in Fig. 3. Trichuris carriage ( $75 \%$ of all carriers) predominates, followed by ascaris $(44 \%)$. Mixed infestations are common $(31 \%)$. The infestation pattern is quite distinct from that of the Indians and Pakistanis above.

\section{THE AMERICAS}

There were 1,069 children from this region, of whom 1,058 came from the West Indies, mainly from Jamaica with a sprinkling from the other islands. Their age range was 4 to 16 years with an equal sex ratio. The infestation patterns of the sexes are similar, and so for simplicity the combined infestation rates for boys and girls are given in Table I and Fig. 4.

Just over half the children ( $51 \%$ ) harbour parasites. Trichuris is carried by $78 \%$ of the positives and ascaris by $40 \%$; hymenolepis were not found. The one child harbouring Sch. mansoni had been born in French Guiana, had migrated to St. Lucia-a known endemic focus of schistosomiasis-and came to the U.K. at the age of 15. Mixed infestations are present in $36 \%$ of carriers-18\% harbour trichuris with ascaris, $8 \%$ harbour hookworm with trichuris, and $8 \%$ have hookworm, trichuris, and ascaris.

The pattern of carriage in the West Indian population is oddly similar to that in the Hong Kong population.

\section{AFRICAN REGION}

There were 616 children from this region, of whom 475 came from Kenya, 67 from Uganda, and small numbers from many other areas (see minor populations).

The Kenyan population comprised roughly equal numbers of boys and girls with ages between 4 and 17 years, and their car- 
riage of helminths was similar. The infestation pattern of this group is shown in Table I and the mixed infestations in Fig. 5. These children have a much lower carriage rate $(16 \%)$ than that of the Asian or American populations tabulated above, and hookworm, hymenolepis, ascaris, and trichuris each contribute a substantial percentage to the total.

The Ugandans show an even lower carriage rate $(7 \%)$ than the Kenyans and probably on this account, as well as the small size of the population examined ( 67 children), some species of worms are not represented. Also with these small numbers the percentages given have large standard errors.

\section{MINOR POPULATIONS}

There were 33 countries or areas which contributed fewer than 20 children each to the total examined. Ceylon contributed 2, Malaysia (and Singapore) 7, British Columbia 1, U.S.A. 1, Venezuela 2, Guyana 7, Libya 1, Tanzania 19, Zambia 6, Malawi 1, "other" East African areas 10, Sierra Leone 4, Ghana 4, Nigeria 6, "other" Central African areas 4, "other" West African areas 1, South Africa 16, Seychelle Islands 2, Aden 6, Yemen 12, Israel 2, Turkey 2, Morocco 1, Iraq 1, Iran 6, Saudi Arabia 2, Cyprus 10, Spain 2, Italy 3, Gibraltar 1, Poland 1, Yugoslavia 1, and Hungary 1.

These together total 145 children, of whom 25 carried one or more helminth species. The numbers derived from each country are too small to be of much significance, but of 12 children from the Yemen four carried $A$. lumbricoides and one a mixture of ascaris, trichuris, and Sch. mansoni; and of four from Sierra Leone all were carriers, two ascaris, one hookworm, and one mixture of ascaris and trichuris. The one child from Gibraltar harboured hookworm and trichuris.

\section{Hookworm Identification and Protozoal Cysts}

During the survey a consecutive series of 124 hookworm-ovapositive specimens were cultured for identification; the details are given in Table II. One boy from Pakistan carried both types of hookworm.

TABLE II-Relationship of Country of Origin to Type of Hookworm Carried

\begin{tabular}{|c|c|c|c|c|c|c|c|}
\hline \multicolumn{6}{|c|}{ Country } & \multirow{2}{*}{$\begin{array}{c}\text { Ancylostoma } \\
27 \\
70 \\
0 \\
0 \\
0\end{array}$} & \multirow{2}{*}{$\begin{array}{c}\text { Necator } \\
0 \\
1^{*} \\
25 \\
1 \\
1\end{array}$} \\
\hline $\begin{array}{l}\text { India } \ldots \\
\text { Pakistan .. } \\
\text { West Indies } \\
\text { Sierra Leone } \\
\text { Tanzania .. }\end{array}$ & $\begin{array}{l}\cdots \\
\cdots \\
\cdots \\
\cdots\end{array}$ & $\begin{array}{l}\cdots \\
\because \\
\cdots \\
\cdots\end{array}$ & $\begin{array}{l}\cdots \\
\cdots \\
\cdots \\
\cdots\end{array}$ & $\begin{array}{l}\ldots \\
\ldots \\
\cdots\end{array}$ & $\begin{array}{l}. \\
\because \\
\because \\
\therefore\end{array}$ & & \\
\hline
\end{tabular}

* One boy had both types of hookworm.

Although cysts of Entamoeba coli, Iodamoeba bütschlii, Endolimax nana, and Giardia lamblia were seen, only those of the potentially pathogenic organism $G$. lamblia are recorded. No $E$. histolytica cysts were found-probably because only one wet preparation from each child was scanned.

Of 2,709 faecal samples examined, 250 contained cysts of G. lamblia; this gives a total crude infestation rate of $9 \%$; the figures being similar for the two sexes. The findings for different regions are summarized in Table III.

TABLE III-Giardia lamblia Carriage Rates Related to Region of Carriers

\begin{tabular}{|c|c|c|c|c|c|}
\hline \multicolumn{4}{|c|}{ Region } & \multirow{2}{*}{$\begin{array}{c}\text { Total Examined } \\
1,611 \\
739 \\
313 \\
36 \\
10\end{array}$} & \multirow{2}{*}{$\begin{array}{c}\text { No. (\% Positive) } \\
183(11) \\
34(5) \\
24(8) \\
7(19) \\
2(20)\end{array}$} \\
\hline $\begin{array}{l}\text { South-east Asia } \\
\text { The Americas } \\
\text { African region ... } \\
\text { East Mediterranean } \\
\text { West Mediterranean }\end{array}$ & $\begin{array}{c}. \\
\cdots \\
\ddot{E} \\
\text { Europe }\end{array}$ & $\begin{array}{l}\ldots \\
\because \\
\because \\
\ldots\end{array}$ & $\begin{array}{l}\ldots \\
\because \\
\cdots\end{array}$ & & \\
\hline Total & . & $\ldots$ & . & 2,709 & $250(9)$ \\
\hline
\end{tabular}

The pattern of carriage of giardia proved to be quite different from the carriage of the helminths. In Table III children from the South-east Asian region have not been distinguished by country of origin or sex because the carriage rates are almost the same for all countries. For instance, there is a carriage rate of $13 \%$ for both boys and girls from Pakistan; and of $12 \%$ for boys and $11 \%$ for girls from India.

The carriage rate for the Americas (mainly West Indies) is slightly lower, at $5 \%$, than for South-east Asia but there are no sex differences. The African region (mainly Kenya and Uganda) has a carriage rate of $8 \%$ for boys and girls. In the East Mediterranean area (which includes countries from Turkey to Iran) the carriage rate is $19 \%$ (S.E. \pm 6.5 ) and in the European West Mediterranean area it is $20 \%$ (S.E. $\pm 12 \cdot 6$ ). These last two percentages are based on small numbers of children and the standard errors (S.E.) are large.

\section{Discussion}

\section{BACTERIA}

We found a salmonella carriage rate of 1.25 per 1,000 , a figure similar to that given for a normal population of 8,748 children (under 5 years old) in the U.K. (P.H.L.S. Report, 1959). However, in the present survey two of the five salmonellas were S. typhi, which did not figure in the P.H.L.S. Report; this is in keeping with the reported findings in Bradford (Turner, 1970) of two symptomless excreters in 5,000 immigrant children, and suggests that these organisms may have been acquired abroad. The carriage rate for shigellas was also 1.25 per 1,000 and thus lower than the 4 per 1,000 given in the P.H.L.S. Report.

The carriage of $S$. typhi in children of school age poses an awkward problem for an M.O.H. He finds himself sailing between the Scylla of allowing a carrier to attend school and the Charybdis of impairing that child's education and subjecting it to useless and possibly dangerous treatment of a medical or even of a surgical nature. Both situations abound with political, social, and medical overtones of an unpleasant sort, which are largely due to ignorance of the nature of typhoid and how it spreads. The problem has been put in its correct perspective by Dr. E. S. Anderson (1971). Fortunately both our S. typhi excreters became negative and were returned to school after two months. They have been re-examined on a number of occasions and have remained negative. Thus the situation facing the M.O.H. at Derby reported in The Times (1971) and in the British Medical fournal (1971), where two child typhoid carriers have been excluded from school, has not arisen.

It is generally supposed that excretion of the "classical" $V$. cholerae rarely persists beyond two weeks (Bart and Mosley, 1970), but occasionally, symptomless persons may excrete the El Tor biotype for several months (Barua, 1969). Furthermore, family studies of $V$. el tor infection in a Calcutta slum suggest that young children may play a part in maintaining infection in the community (Sen et al., 1968). However, in our small series no carriage of either vibrio biotype was found.

Woodruff (1968) suggested that helminths may play a part as "synergists" in promoting the carriage of vibrios and salmonellas. In our series of five salmonella excreters, only one was shown to be carrying helminths; of the five shigella excreters found, four also carried worms. No conclusions are possible on the basis of this small sample.

\section{HELMINTHS}

Using a simple concentration method on a single specimen, we obtained a crude infestation rate of $37 \%$, roughly twice that found in a comparable survey in the City of Bradford. There the infestation rate in 1,317 children was $18.6 \%$, based on the microscopical examination of an unconcentrated faecal smear 
(Archer et al., 1965). By comparison our figure of $37 \%$ is surprisingly high, and as examination of a single specimen must be regarded only as putting a lower limit on the number infested, a more thorough search would doubtless have yielded more positives.

The various regions covered by our survey contributed roughly equal numbers of boys and girls with the single exception of Pakistan, where boys outnumbered girls by five to one. This exception presumably has a sociological basis which may extend to the finding of a greater hookworm carriage rate in boys, whereas the girls of this population have higher carriage rates for both hymenolepis and ascaris. The Pakistani girls and boys thus behave as distinct populations; perhaps the activities of the boys make them more liable to acquire hookworm and the activities of the girls make them prone to acquire hymenolepis and ascaris. We have not determined the reason for these differences.

The regional differences in the carriage patterns have already been considered but the low carriage rate in the African group (Kenya 16\% and Uganda 7\%) contrasts with the high rate in the West Indian group $(51 \%)$ and South-east Asian groups (30$40 \%$ ). The dominance of trichuris infestations and the absence of hymenolepis are notable in those from Hong Kong and the West Indies.

Our figures clearly indicate the need to examine the faeces of all newly arrived immigrant children, using a concentration method when possible. While many infestations are probably light and will disappear in time, they nevertheless require recognition because the carrier may suffer disease. The possibility of medical and surgical manifestations of infestation must be constantly in mind when dealing with these children. Secondly, as has been pointed out by Buckley and Pester (1965) and by Archer et al. (1965), there is a risk of transmission of helminths in this country, and the large number of children infested constitute a substantial reservoir. These authors give five instances where transmission has taken place to children who have never been abroad-three cases of hookworm, one case of hymenolepis, and one case of ascaris-and it must be assumed that other unrecognized instances exist.

The risks of transmission are largely unknown and depend on variable climatic conditions as well as on social circumstance. The hookworm requires warm, humid conditions-a hot wet summer-to develop in earth to the larval infective stage which then penetrates the skin. Eggs of ascaris and trichuris require only a period for embryonation before becoming infective. Hymenolepis ova require only transmission to the mouth for infection. In a recent study in Prague (Kawaciuková, 1971) eggs of Enterobius vermicularis were found in modern heated swimming pools; the author also stated that the ova of ascaris, trichuris, and hookworm will mature despite a chlorination level of $0 \cdot 2-0.3 \mathrm{mg} /$ litre-that is, $0 \cdot 2-0.3$ p.p.m.-residual chlorine, which is adequate for bacteriological purposes. We have incidentally observed that these eggs will continue to embryonate even in $10 \%$ formalin in the laboratory. Thus it cannot be assumed that disinfectants used against bacteria will necessarily be effective against helminth ova.

Finally, the difficulty of ensuring effective treatment of these children is a real one. Many have not got doctors of their own; there are often substantial language barriers which make intelligible instructions hard to give and effective eradication of worms hard to ensure. Early in the survey we referred positives to a hospital so that we could be certain that they got treatment and with the correct anthelmintics, but we do not know whether the medications prescribed were actually taken and it has not proved practicable to follow the children up to find out whether the treatment was effective.

We are much indebted to Dr. E. L. M. Millar, M.O.H. of Birmingham, for his continuing support and interest. Thanks are also due to the staff of the School Health Service and Public Health Laboratory for their co-operation. In particular we must mention the nurses at Canterbury House School Clinic and the education welfare officers, without whose perseverance many of the specimens would not have been obtained.

\section{References}

Anderson, E. S. (1971). The Times, 31 December 1971. Archer, D. M., Bamford, F. N., and Lees, E. (1965). British Medical

Barua, D. (1969). Quoted in Lancet, 2, 195.

Bart, K. J., and Mosley, W. H. (1970). Lancet, 2, 47.

British Medical fournal, 1971, 4, 507.

Buckley, J. J. C., and Pester, F. R. N. (1965). British Medical fournal, 2, 106. Carpenter, K. P. (1966). Monthly Bulletin of the Ministry of Health and the Public Health Laboratory Service, 25, 58.

Hsieh, H. C. (1963). World Health Organization. Technical Report Series, No. 255, Annex 3.

Kawaciuková, J. (1971). Československá Epidemiologie, Mikrobiologie, Immunologie, 20, 156

P.H.L.S. Report (1959). Monthly Bulletin of the Ministry of Health and the Public Health Laboratory Service, 18, 86.

Sasa, M., Hayashi, S., Tanaka, H., and Shirasaka, R. (1958). Japanese Journal of Experimental Medicine, 28, 129.

Sen, R., Sen, D. K., Chakrabarty, A. N., and Ghosh, A. (1968). Lancet, 2,

The Times, 17 November 1971.

Thompson, R. G. (1972). Fournal of Clinical Pathology. In press.

Turner, W. (1970). Quoted in Medical Officer, 124, 90 .

W.H.O. Report (1964). World Health Organization. Technical Report Series, No. 277 .

Woodruff, A. W. (1968). Transactions of the Royal Society of Tropical Medicine and Hygiene, 62, 446.

\title{
Aerosol Hazards from Some Clinical Laboratory Apparatus
}

\author{
D. A. RUTTER, C. G. T. EVANS
}

British Medical fournal, 1972, 1, 594-597

\section{Summary}

Infectious diseases, such as infectious hepatitis, may be transmitted from patients to staff in clinical laboratories and dialysis units during the performance of necessary procedures. This prompted us to examine the propensity of several items of commonly used apparatus to produce aerosols of infected blood. These were a microhaematocrit

Microbiological Research Establishment, Porton, Salisbury, Wiltshire

D. A. RUTTER, M.B., B.CHIR., Senior Scientific Officer

C. G. T. EVANS, M.SC., M.I.BIOL., Principal Scientific Officer meter. We also compared some blood sample tubes with two types of lid. The results showed that all of these are potential sources of infection for laboratory staff.

\section{Introduction}

"It may be stated without fear of contradiction that every infectious microbiological agent which has been studied in the laboratory has, at one time or another, caused infection of operators" (Chatigny and Clinger, 1969). The recent epidemics of infectious hepatitis in several British hospitals, with fatal sequelae, have underlined yet again the readiness with which 